\title{
RINCK-mediated monoubiquitination of cGAS promotes antiviral innate immune responses
}

\author{
Zhao-Shan Liu' ${ }^{1}$, Zi-Yu Zhang ${ }^{1}$, Hong Cai ${ }^{1}$, Ming Zhao' ${ }^{1}$, Jie Mao ${ }^{1}$, Jiang Dai ${ }^{1}{ }^{12}$, Tian Xia ${ }^{1}$, Xue-Min Zhang ${ }^{1,2}$ \\ and Tao $\mathrm{Li}^{1 *}$ (1)
}

\begin{abstract}
Background: As an important danger signal, the presence of DNA in cytoplasm triggers potent immune responses. Cyclic GMP-AMP synthase (cGAS) is a recently characterized key sensor for cytoplasmic DNA. The engagement of cGAS with DNA leads to the synthesis of a second messenger, cyclic GMP-AMP (cGAMP), which binds and activates the downstream adaptor protein STING to promote type I interferon production. Although cGAS has been shown to play a pivotal role in innate immunity, the exact regulation of cGAS activation is not fully understood.

Results: We report that an E3 ubiquitin ligase, RING finger protein that interacts with C kinase (RINCK, also known as tripartite motif protein 41, TRIM41), is critical for CGAS activation by mediating the monoubiquitination of cGAS. Using CRISPR/Cas9, we generated RINCK-deletion cells and showed that the deficiency of RINCK resulted in dampened interferon production in response to cytosolic DNA. Consistently, the RINCK-deletion cells also exhibited insufficient interferon production upon herpes simplex virus 1, a DNA virus, infection. As a result, the viral load in RINCK-deficient cells was significantly higher than that in wild-type cells. We also found that RINCK deficiency inhibited the up-stream signaling of DNA-triggered interferon production pathway, which was reflected by the phosphorylation of the TANKbinding kinase 1 and the interferon regulatory factor 3. Interestingly, we found that RINCK binds to cGAS and promotes the monoubiquitination of CGAS, thereby positively regulating the cGAS-mediated cGAMP synthesis.
\end{abstract}

Conclusions: Our study reveals that monoubiquitination is an important regulation for CGAS activation and uncovers a critical role of RINCK in the cGAS-mediated innate immunity.

Keywords: RINCK, Monoubiquitination, CGAS, Innate immunity, Antiviral immunity

\section{Background}

The innate immune system protects host from infections by detecting microbials and eliciting immediate immune responses [1]. The pattern-recognition receptors (PRRs) of the host are responsible for the effective recognition of danger signals from microbial [2, 3]. These danger signals, such as nucleic acids and toxins, are collectively called pathogen-associated molecular patterns (PAMPs).

\footnotetext{
*Correspondence: tli@ncba.ac.cn

1 State Key Laboratory of Proteomics, Institute of Basic Medical Sciences, National Center of Biomedical Analysis, 27 Tai-Ping Rd., Beijing 100850, China

Full list of author information is available at the end of the article
}

Although the cells evolved different kinds of PRRs for different PAMPs, the detection of nucleic acids provides the most efficient mechanism to sense invade microbials $[2$, 4].

Normally the DNA of eukaryotic cells is restricted in the nucleus or the DNA-containing organelle, mitochondrion. Upon infections, DNA of microbials will present in the cytoplasm and can be quickly detected by the host [4]. Recent study identifies cGAS as a key sensor for cytosolic DNA $[5,6]$. When engaged with DNA, cGAS is activated and catalyzes the synthesis of cGAMP, which is a second messenger molecule that binds and activates stimulator of interferon genes (STING) [7-9]. The activated STING then recruits TBK1, which further activates

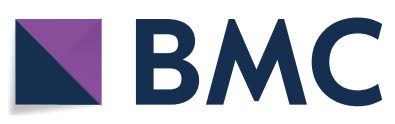

(c) The Author(s) 2018. This article is distributed under the terms of the Creative Commons Attribution 4.0 International License (http://creativecommons.org/licenses/by/4.0/), which permits unrestricted use, distribution, and reproduction in any medium, provided you give appropriate credit to the original author(s) and the source, provide a link to the Creative Commons license, and indicate if changes were made. The Creative Commons Public Domain Dedication waiver (http://creativecommons.org/ publicdomain/zero/1.0/) applies to the data made available in this article, unless otherwise stated. 
the downstream transcription factors, IRF3 and NF- $\mathrm{kB}$, to initiate the production of type I interferons and other inflammatory cytokines [10].

Since cGAS is a key sensor of cytosolic DNA in many cell types, the activation of cGAS must be tightly controlled. The dysregulation of cGAS activation has been implicated in several autoimmune diseases [11]. For example, cells are constantly exposed to genomic stresses, which give rise to the emergence of DNA fragments in the cytoplasm [12]. DNases, such as DNA Three prime Repair Exonuclease 1 (TREX1), are responsible for the degradation of cytosolic DNAs to prevent the autoimmune responses [13-15]. The deletion of Trex1 in mice resulted in lethal autoimmune conditions [14]. Importantly, when crossed with cGAS knock-out mice, the TREX1-deficiency-induced lethality of Trex $1^{-/-}$mice is fully rescued [16]. This indicates that the uncontrolled cGAS activation is the major cause of TREX1-deficiencyinduced death. Moreover, the aberrant activation of cGAS is also linked to other autoimmune diseases and aging $[17,18]$. Thus, understand the regulation of cGAS activity is important for designing strategies to treat the cGAS-related diseases.

It has been reported that autophagy plays a critical role in regulating cGAS activation [19]. Post-translational modifications have also been shown to be important for cGAS regulation. For instance, Akt (also known as protein kinase B)-mediated cGAS phosphorylation inhibits cGAS activation in the late phase of DNA treatment and thus contributes to turning off the signaling [20]. Glutamylation has been reported to be an important regulation of cGAS [21]. Protein ubiquitination is a key regulatory modification in a variety of biological processes, including innate immune responses [22]. Ubiquitin is a highly conserved 76-amino-acid protein, and the addition of ubiquitin on a substrate protein is called ubiquitination. Protein can be modified by either a single ubiquitin (monoubiquitination) or a ubiquitin chain (polyubiquitination). An ubiquitin contains seven lysine (K) residues (K6, K11, K27, K29, K33, K48 and K63) [23]. When the polyubiquitination chain forms, the secondary ubiquitin is always linked to one of the seven lysine residues or the N-terminal methionine $(\mathrm{M})$ of the previous ubiquitin. Similar to ubiquitination on other proteins, the K48-linked polyubiquitination initiates the degradation of cGAS, and the K27-linked polyubiquitination of cGAS mediated by the E3 ubiquitin ligase RNF185 promotes the enzymatic activity of cGAS $[24,25]$. In this study, we found that E3 ubiquitin ligase RINCK plays an important role in cytosolic DNA and DNA virus-induced immune responses. Silencing of RINCK attenuated cytosolic DNA-triggered interferon production. Further, RINCK positively regulates cGAMP synthesis by mediating the monoubiquitination of cGAS. Our findings revealed that monoubiquitination is an important regulation for cGAS activation and uncovers a critical role of RINCK in the cGAS-mediated innate immunity.

\section{Results \\ RINCK is required for cytosolic DNA-induced type I interferon production}

To understand the detailed regulation of cGAS activation, we analyzed the interacting proteins of cGAS with a liquid chromatography-mass spectrometry (LC-MS/MS) approach. To do so, we expressed Flag-tagged human cGAS in cells and cGAS was immunoprecipitated with anti-Flag agarose beads. The co-precipitated proteins were separated by SDS-PAGE and further analyzed with LC-MS/MS. Among the identified proteins we selected several candidates and focused on RINCK in this study.

Since cGAS is a key DNA sensor, we first examined whether RINCK is involved in DNA-induced Type I interferon produce. Using clustered regularly interspaced short palindromic repeats (CRISPR)/Cas9 technology, we generated RINCK-deficient U937 (human monocytic cell) cells (Fig. 1a). We challenged the RINCK-deficient cells by introducing herring testis DNA (HT-DNA) into the cytoplasm and then detected the interferon production by quantitative PCR (qPCR) (Fig. 1b). We found that the interferon production level was significantly inhibited in RINCK knockout cells, compared to that of wild type (WT) cells. Consistent results were obtained when the cells were treated with interferon stimulatory DNA (ISD) (Fig. 1c). We further used enzyme-linked immunosorbent assay (ELISA) to measure the secreted interferon- $\beta$, our data show that the deletion of RINCK resulted in the dampened interferon- $\beta$ synthesis in response to cytoplasmic DNA treatment (Fig. 1d, e). Thus, RINCK is critical for the type I interferon production induced by cytosolic DNA. We next examined whether the expression of RINCK mRNA is inducible in response to HT-DNA or interferon- $\beta$ treatment. Our results showed that the expression of RINCK was not induced by interferon or cytosolic DNA treatment, while a known ISG, Rsad2, was dramatically induced (Fig. 1f, g).

\section{RINCK deficiency attenuates cytosolic DNA-triggered cGAS/STING signaling}

To determine the role of RINCK in the DNA-triggered signaling pathway, we detected the activation of cGAS/ STING signaling, which can be reflected by the phosphorylation of IRF3 and its kinase, TBK1. In line with our above findings, the deletion of RINCK led to significantly inhibited activation of IRF3 and TBK1 (Fig. 2a, b). To further confirm these observations, we used HeLa cells to study the role of RINCK in the cytosolic DNA-induced 


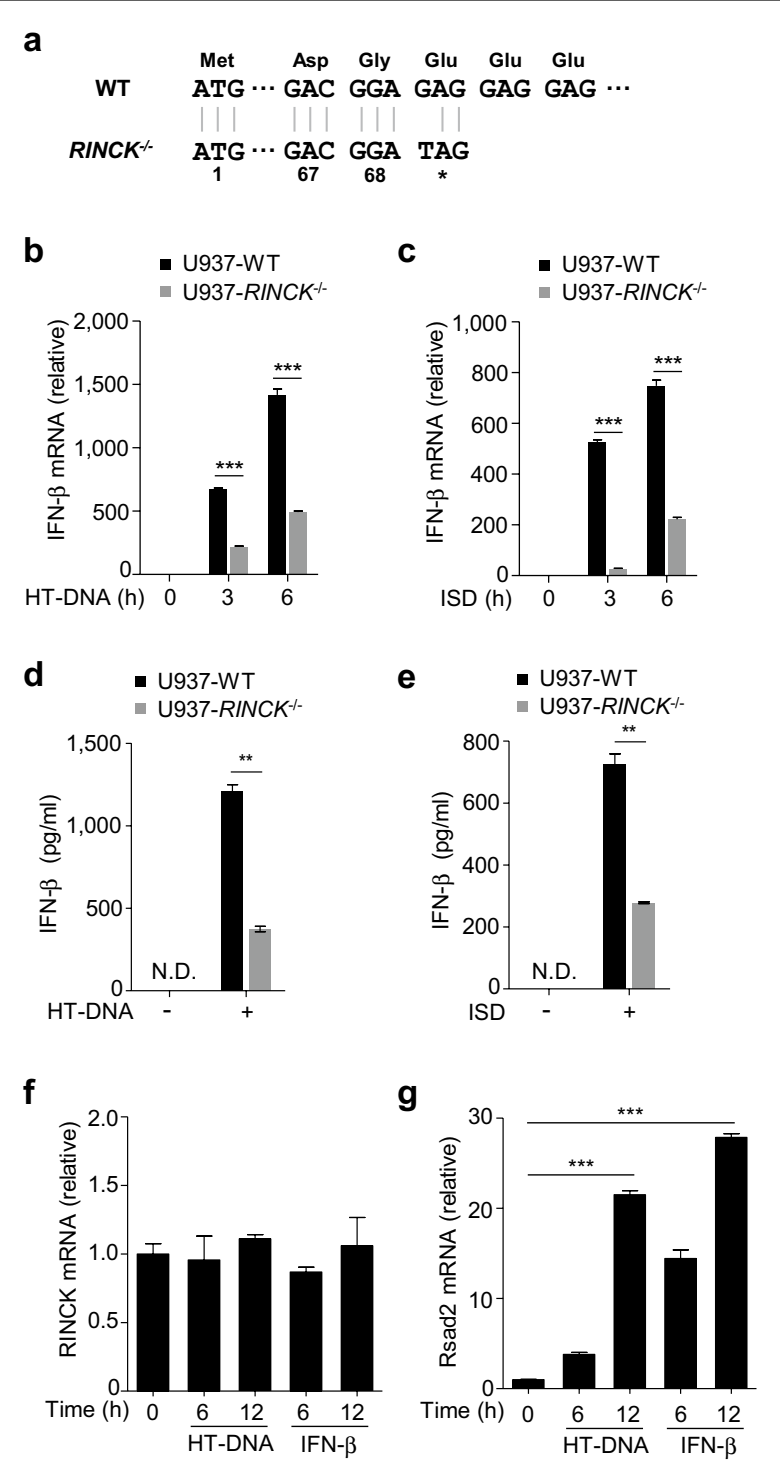

Fig. 1 RINCK is required for cytosolic DNA-induced type I interferon production. a Schematic drawing of the RINCK deletion in U937 cells. b, cWT or RINCK-deficient U937 cells were treated with HT-DNA or ISD for indicated time followed by measuring interferon (IFN)- $\beta$ mRNA with qPCR. $\mathbf{d}$, e WT or RINCK-deficient U937 cells were treated with HT-DNA or ISD for $12 \mathrm{~h}$, and the culture medium was collected for quantification of IFN- $\beta$ by ELISA. $\mathbf{f}, \mathbf{g}$ U937 cells were treated with HT-DNA or IFN- $\beta$ for indicated time followed by measuring mRNA levels of RINCK and Rsad2 with QPCR. Data are presented as the mean $\pm S D .{ }^{*} P<0.01,{ }^{* * *} P<0.001$. N.D., not detected. Data represent three independent experiments

cGAS/STING signaling, as HeLa cells were previous used to study cGAS function [19]. We treated HeLa cells with siRNAs targeting RINCK or the control siRNAs for $48 \mathrm{~h}$ to efficiently knockdown the expression of RINCK (Fig. 2c). We found that knockdown of RINCK markedly attenuated the DNA-triggered phosphorylation of
IRF3 and TBK1 (Fig. 2d). These data suggest that RINCK is required for the DNA-induced activation of cGAS/ STING signaling.

\section{RINCK is required for CGAMP synthesis}

The engagement of cGAS with DNA leads to cGAS activation and the synthesis of cGAMP [5], which binds and activates the downstream adaptor protein STING and induces the phosphorylation of IRF3 and TBK1 [8]. To study how RINCK regulates cGAS/STING pathway, we used commercial cGAMP to treat both WT and RINCKdeficient cells. Our results show that cGAMP induced similar levels of the interferon production (Fig. 3a) and the phosphorylation of TBK1 and IRF3 (Fig. 3b). These data suggest that RINCK regulates cGAS/STING signaling at the cGAS level. We next assessed the whether RINCK regulates cGAS enzymatic activity. To do so, we established an approach to quantify cGAMP in cells by using the liquid chromatography-mass spectrometry/ multiple reaction monitoring (LC-MS/MRM) (Fig. 3c). With this method, we measured the cGAMP synthesis in cells in response to HT-DNA treatment. We found that the production of cGAMP in RINCK-deficient cells was significantly decreased (Fig. 3d). Thus, RINCK appears to regulate the activity of cGAS directly.

\section{RINCK mediates the monoubiquitination of CGAS}

To further understand the mechanism by which RINCK regulates cGAS activation, we first examined the interaction of cGAS with RINCK. We transfected Flag-tagged human cGAS and HA-tagged RINCK into HEK293T cells and analyzed their interaction with immunoprecipitation. Consistent with our MS identification, the interaction of cGAS and RINCK was detected (Fig. 4a). Since RINCK is a known E3 ligase for ubiquitination [26], we then tested whether the presence of ubiquitin will enhance the interaction of cGAS and RINCK. Unexpectedly, when ubiquitin was co-transfected with cGAS and RINCK, we found that there was a band emerged above cGAS that can also be recognized by cGAS antibody (Fig. 4b). This result suggests that cGAS is likely modified by ubiquitin. By expressing the green fluorescence protein (GFP)-tagged cGAS with RINCK and ubiquitin, we confirmed this modification (Fig. 4c). Based on the shifted size of the modification band, we reasoned that the modification may be monoubiquitination [27]. To further confirm this, we used the $\mathrm{K} 0$ mutant of ubiquitin, in which all the seven Lysines were mutated to Arginin (R) and thus can only form monoubiquitination on target proteins [23]. With ubiquitin-K0, we confirmed that RINCK catalyzed the monoubiquitination of cGAS (Fig. 4d). Previous study showed that the C20A mutation blocks RINCK enzymatic activity [26]. Using RINCK $^{\mathrm{C} 20 \mathrm{~A}}$ 


\section{a}

\begin{tabular}{|c|c|c|}
\hline U937 & WT & RINCK $^{-1}$ \\
\hline -DNA(I) & & \\
\hline
\end{tabular}

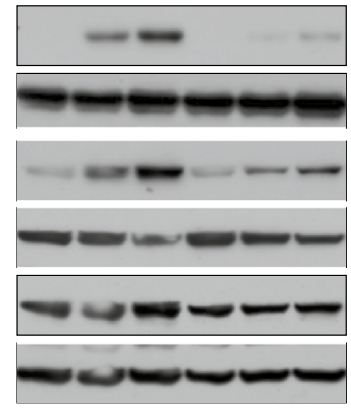

IB: p-IRF3

IB: IRF3

IB: $p-T B K 1$

IB: TBK1

IB: cGAS

IB: $\alpha$-Tubulin b

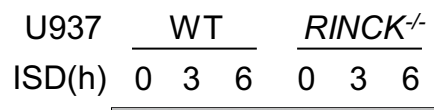



C

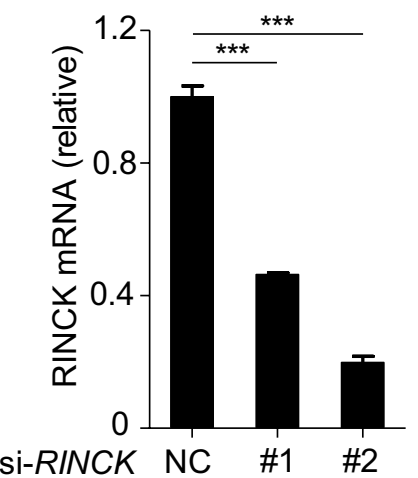

d

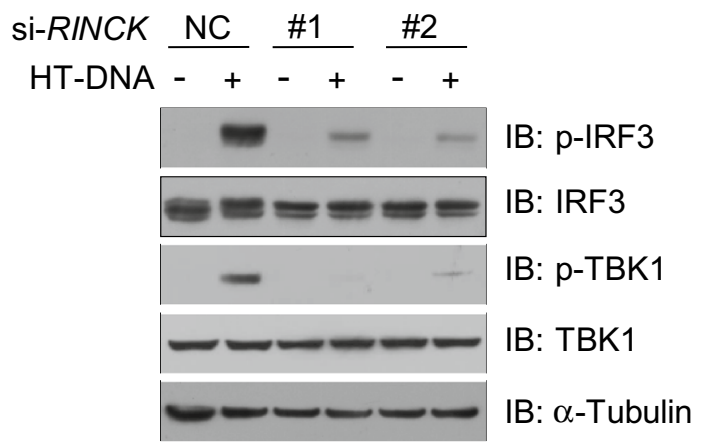

Fig. 2 RINCK deficiency attenuates cytosolic DNA-triggered cGAS/STING signaling. a, b WT or RINCK-deficient U937 cells were treated with HT-DNA or ISD for indicated time followed by immunoblotting with indicated antibodies. $\mathbf{c}$ HeLa cells were transfected with the negative control (NC) or RINCK siRNAs for $48 \mathrm{~h}$ followed by measuring RINCK mRNA with qPCR. $\mathbf{d}$ HeLa cells were transfected with the negative control (NC) or RINCK siRNA for $48 \mathrm{~h}$ and then were treated with HT-DNA for $3 \mathrm{~h}$ followed by immunoblotting with indicated antibodies. Data are presented as the mean \pm SD. *** $P<0.001$. Data represent three independent experiments

mutant, we found that the mutated RINCK failed to mediate the monoubiquitination of cGAS (Fig. 4e). Together, these data suggest that RINCK mediates cGAS monoubiquitination. By co-expression of RINCK, ubiquitin and cGAS together, we found that WT RINCK, but not the RINCK ${ }^{\mathrm{C} 20 \mathrm{~A}}$ mutant, dramatically increased cGAMP production in cells (Fig. 4f). Therefore, RINCK promotes cGAS activation by mediating the monoubiquitination of cGAS.

\section{RINCK promotes anti-DNA virus innate immune responses} Since cGAS plays crucial role in anti-DNA virus immunity [28], we examined the role of RINCK in antiviral innate immune responses. We infected RINCK-deficient U937 cells with HSV-1, a DNA virus [29], and measured the interferon- $\beta$ mRNA transcription by qPCR. Our results show that the interferon production was significantly reduced in RINCK knockout cells, compared to that in WT cells (Fig. 5a). We have also detected HSV-1 abundance by measuring the virus RNA transcription and found that HSV-1 RNA in RINCK-deficient cells was much higher than that in WT cells (Fig. 5b). Consistently, by performing the plaque assay, we found that RINCK deletion resulted in an increased HSV-1 virus load in cells (Fig. 5c, d). Taken together, these data indicate that RINCK is important for antiviral responses.

\section{Discussion}

As a key DNA sensor, cGAS is crucial for immune defense against bacteria and virus infection [30]. Although cGAS has been shown to play a pivotal role in innate immunity, the exact regulation of cGAS activation is not fully understood. Our finding that RINCK positively regulates cGAS activation by mediating the monoubiquitination of cGAS uncovers the function of RINCK in cGAS-mediated innate immunity. The deficiency of RINCK resulted in dampened interferon production in response to cytosolic DNA or DNA virus infection. Recent studies showed that 
a

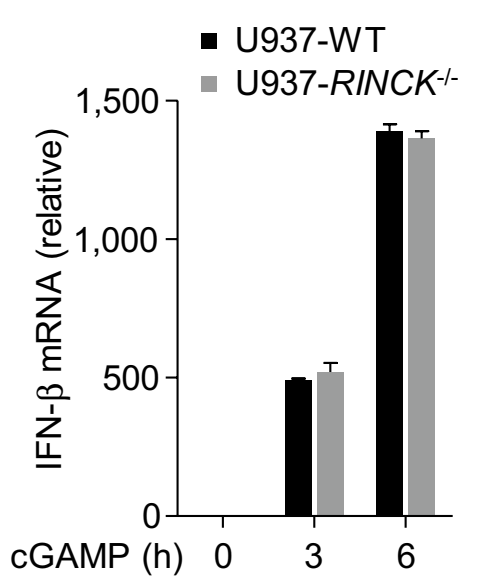

b

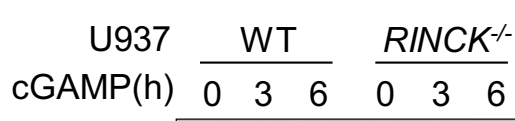

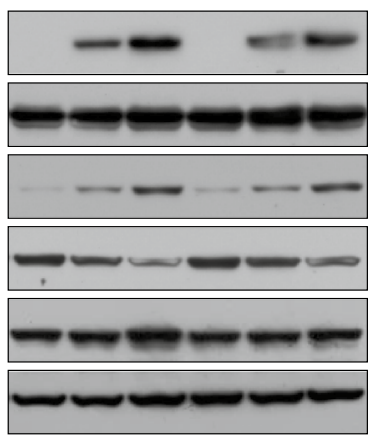

IB: p-IRF3

IB: IRF3

IB: $\mathrm{p}-\mathrm{TBK} 1$

IB: TBK1

IB: cGAS

IB: $\alpha$-Tubulin
C

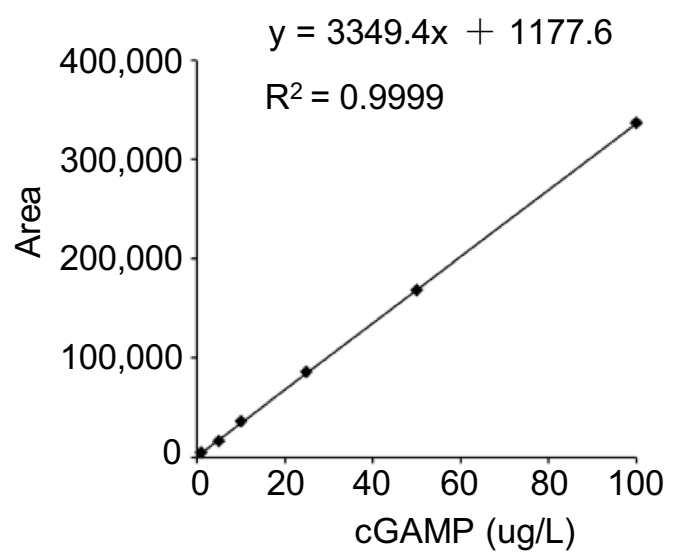

d

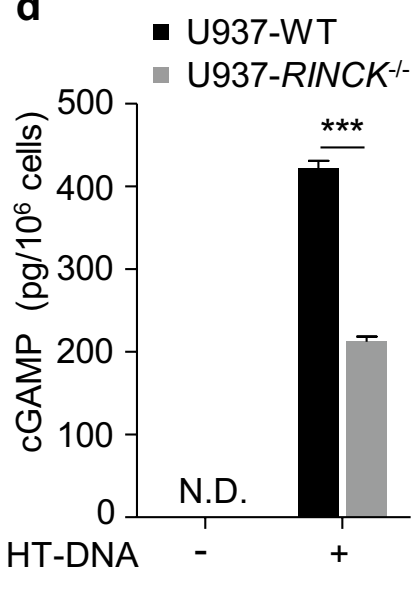

Fig. 3 RINCK is required for CGAMP synthesis. a WT or RINCK-deficient U937 cells were treated with cGAMP for indicated time followed by measuring IFN- $\beta$ mRNA with qPCR. b WT or RINCK-deficient U937 cells were treated with cGAMP for indicated time followed by immunoblotting with indicated antibodies. c Standard curve for CGAMP quantification by LC-MS/MRM. d WT or RINCK-deficient U937 cells were treated with HT-DNA for $6 \mathrm{~h}$ and the cell extract was collected for quantification of CGAMP by LC-MS/MRM. Data are presented as the mean \pm SD. ${ }^{* * *}<<0.001$. N.D., not detected. Data represent three independent experiments

the deletion of cGAS fully rescued the self-DNA-induced autoimmunity [16], suggesting that inhibition of chronic activation of cGAS is critical for treating these diseases. On the other hand, effective activation of cGAS will also be important for antiviral immunity $[28,31]$. Therefore, understand the detailed regulation of cGAS provide more targets for designing strategies to treat autoimmune diseases or viral infections.

Ubiquitination has been reported to play a pivotal role in modulating innate immune pathways, such as the retinoic acid-inducible gene I (RIG-I)-like receptor pathway, Toll-like receptor pathway, as well as the intracellular DNA sensing pathway [22, 32, 33]. Accumulating evidences suggested that more and more members of the tripartite motif (TRIM) family, which comprises about 70 proteins, are involved in pathogen-recognition and in host defenses [34, 35]. TRIM25 mediates the K63-linked ubiquitination of RIG-I and promotes the RIG-I-MAVS interaction to ensure the effective immune responses to RNA virus. The K63-linked ubiquitination of STING mediated by TRIM56 and TRIM32 promotes TBK1STING interaction upon infection with Sendai virus $(\mathrm{SeV})$ or HSV-1. RINCK is also a TRIM family member, TRIM41, localizes in both cytoplasm and nucleus, and is comprised of a RING, B-box and coiled-coil domain (CCD) [26]. It has been reported that RINCK regulates Protein Kinase $\mathrm{C}$ (PKC) signaling through ubiquitination [26]. Additionally, RINCK has also been shown to 
a

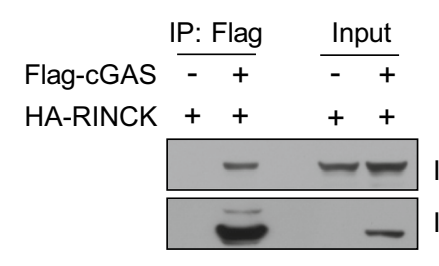

b
Flag-cGAS +++
Myc-Ub - + +
HA-RINCK - - +

IB: HA

IB: cGAS

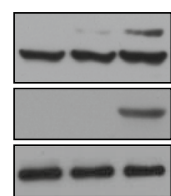

C



IB: cGAS

IB: HA

IB: $\alpha$-Tubulin d



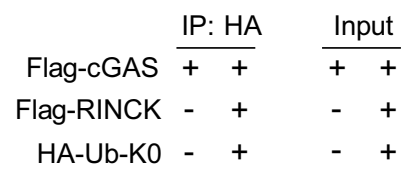



e

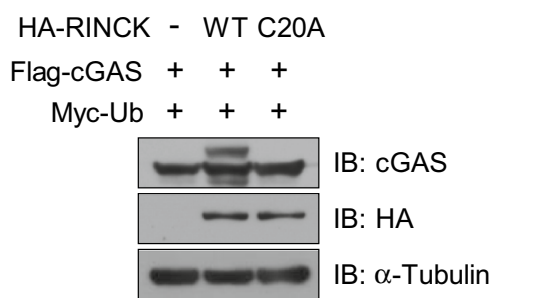

Myc-Ub - + - +

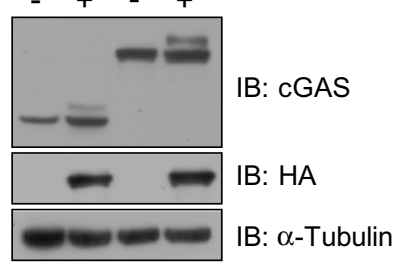

f

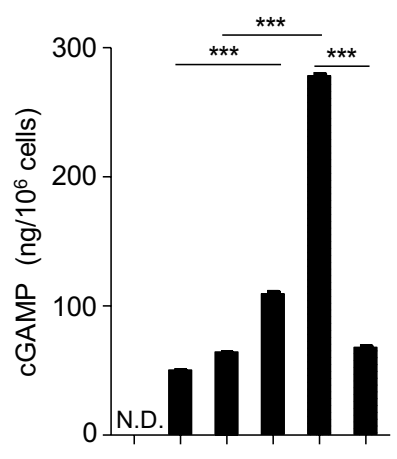

Flag-cGAS -+++++

$\mathrm{Myc}-U \mathrm{~b}+-+-++$

$\mathrm{HA}-\mathrm{RINCK}+-+++$

HA-RINCK-C2OA - $\quad$ - $\quad-\quad-\quad-\quad+$

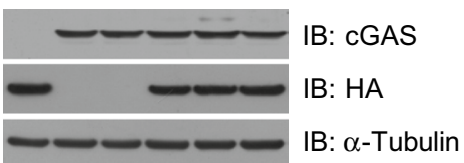

Fig. 4 RINCK mediates the monoubiquitination of CGAS. a HEK293T cells were transfected with indicated plasmids for $24 \mathrm{~h}$. Cell lysates were immunoprecipitated with anti-Flag antibody and then immunoblotted with indicated antibodies. b, c HEK293T cells were transfected with indicated plasmids for $24 \mathrm{~h}$. Cell lysates were immunoblotted with indicated antibodies. $\mathbf{d}$ HEK293T cells were transfected with indicated plasmids for $24 \mathrm{~h}$. Cell lysates were immunoprecipitated with anti-HA antibody and then immunoblotted with indicated antibodies. e HEK293T cells were transfected with indicated plasmids for $24 \mathrm{~h}$. Cell lysates were immunoblotted with the indicated antibodies. $\mathbf{f H E K 2 9 3 T}$ cells were transfected with indicated plasmids for $24 \mathrm{~h}$. Cell extract was collected for quantification of cGAMP by LC-MS/MRM. Data are presented as the mean \pm SD. ${ }^{* * *} P<0.001$. N.D., not detected. Data represent three independent experiments

mediate the monoubiquitination of PKC $\varepsilon$ and links EGFR and NF-kB pathways in tumorigenesis [27]. Interestingly, a very recent publication reported that TRIM56 also mediates the monoubiquitination of cGAS [36]. Together with our study, monoubiquitination is likely to be an important regulation for cGAS activation.

Besides monoubiquitination, cGAS has been reported to be regulated by many other post-translational modifications, including phosphorylation, glutamylation, sumoylation, K27-linked and K48-linked polyubiquitinations [20, 21, 24, 25, 37, 38]. These studies, step by step, uncover the precise control of cGAS activation in cells. It remains to be further elucidated how these modifications work together to dynamically modulate cGAS activity. Since aberrant activation of cGAS is implicated in several autoimmune diseases, senescence and tumorigenesis $[16,17,39]$, it will be important to develop means to modulate cGAS activation based on the regulatory mechanisms.

\section{Conclusions}

By identifying that RINCK mediates the monoubiquitination of cGAS, our study uncovers a critical role of RINCK in the cGAS-mediated innate immunity. 

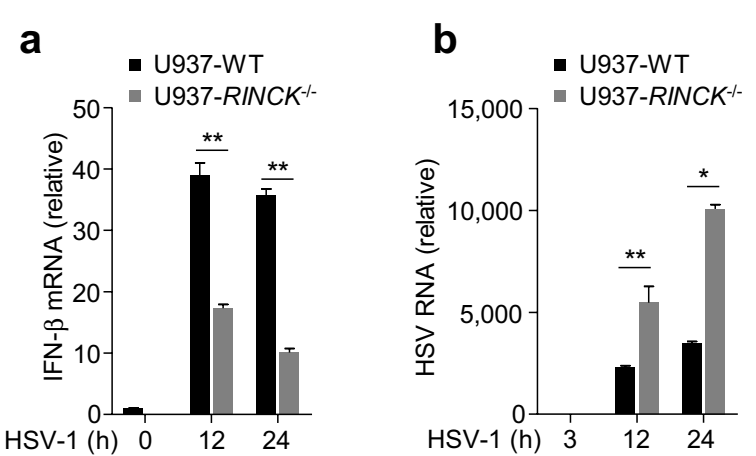

C



\section{d}

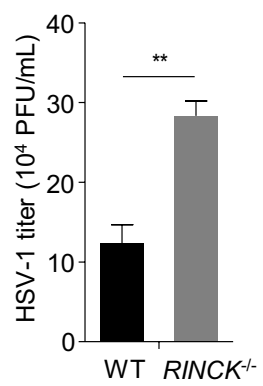

Fig. 5 RINCK promotes anti-DNA virus innate immune responses. a, b WT or RINCK-deficient U937 cells were infected with HSV-1 $(\mathrm{MOI}=1)$ for indicated time followed by measuring IFN- $\beta$ mRNA and HSV-1 RNA with qPCR. cWT or RINCK-deficient U937 cells were infected with HSV-1 $(\mathrm{MOI}=1)$ for $24 \mathrm{~h}$. The replication of HSV-1 was measured by plaque assay in HeLa cells. $\mathbf{d}$ The viral titer (plaque-forming units, PFU) in c was calculated. Data are presented as the mean \pm SD. ${ }^{*} P<0.05,{ }^{* *} P<0.01$. Data represent three independent experiments

\section{Methods}

\section{Reagents}

Anti-p-IRF3 antibody (4947) and anti-TBK1 antibody (3504) were purchased from Cell Signaling; antiIRF3 antibody (ab68481) was from abcam; ISD was synthesized from Invitrogen; cGAMP (tlrl-cga23) was purchased from InvivoGen; anti-HA antibody (sc-7392) was purchased from Santa Cruz Biotechnology; antiFlag M2 affinity gel (a2220), PMA (phorbol 12-myristate 13-acetate; 524400) and HT-DNA (D6898) were purchased from Sigma-Aldrich. Anti-cGAS antibody was prepared in our laboratory.

\section{Cell culture and transfection}

U937 was cultured in RPMI-1640 medium containing $10 \%$ FBS, $2 \mathrm{mM}$ L-glutamine, $100 \mathrm{U} / \mathrm{ml}$ penicillin and $100 \mathrm{mg} / \mathrm{ml}$ streptomycin. HEK293T, HeLa and Vero cells was cultured in Dulbecco's modified Eagle's medium (DMEM) containing 10\% FBS, 2 mM L-glutamine, $100 \mathrm{U} /$ $\mathrm{ml}$ penicillin and $100 \mathrm{mg} / \mathrm{ml}$ streptomycin. U937 cells

were differentiated with PMA $(0.1 \mu \mathrm{M})$ for $36 \mathrm{~h}$ before transfection or other treatment. HT-DNA and ISD treatment were performed with Lipofectamine 2000 (Invitrogen) at a final concentration of $2 \mu \mathrm{g} / \mathrm{ml}$; cGAMP stimulation was performed as previously described $[7,40$, 41], Briefly, cells were incubated with cGAMP $(1 \mu \mathrm{g} / \mathrm{ml})$ for $30 \mathrm{~min}$ at $37^{\circ} \mathrm{C}$ in a permeabilization buffer [50 mM HEPES, pH 7.5; $100 \mathrm{mM} \mathrm{KCl} 33 \mathrm{mM} \mathrm{MgCl} 2 ; 0.1 \mathrm{mM}$ DTT; $85 \mathrm{mM}$ sucrose; $0.2 \% \mathrm{BSA} ; 1 \mathrm{mM}$ ATP and $0.1 \mathrm{mM}$ GTP; $1 \mu \mathrm{g} / \mathrm{ml}$ digitonin (Sigma, D141)]. The permeabilization buffer was replaced with RPMI-1640 medium and cells were further cultured for indicated time. siRNA transfection in HeLa cells was performed with Lipofectamine RNAiMAX (Invitrogen). RNA oligonucleotides for RINCK knockdown are as follows:

Rinck\#1: 5'-ggcgagtgacagaactgaa- $3^{\prime}$

RINCK\#2: 5'-GACACGGTTTCTGGCTGAA-3'.

\section{Generation of CRISPR-Cas9 knockout cell line}

The generation of RINCK deletion U937 cell line was performed as previously described [42]. The guide RNA sequence (Sense: 5'-CGGGGTCCGTGAAGTAATCG-3'; antisense: $5^{\prime}$-CGATTACTTCACGGACCCCG-3') for human RINCK was designed by the online tool from Dr. Feng Zhang's lab (http://crispr.mit.edu/).

\section{Plasmids}

cDNA encoding RINCK, cGAS and Ubiquitin were subcloned into pCDNA3.0-Flag-vector, pXJ40-HA or pXJ40Myc vector for expression in mammalian cells.

\section{Quantitative PCR (qPCR)}

Total RNA was extracted with TRI reagent (93289, Sigma). qPCR was performed on an ABI StepOnePlus system according to manufacturer's protocol. Data was analyzed with StepOnePlus software. Human GAPDH was used for normalization. The primers used to amplify the target genes are listed as follows:

\begin{tabular}{lll}
\hline Gene & $\begin{array}{l}\text { Forward primers } \\
\left(\mathbf{5}^{\prime} \mathbf{-} \mathbf{3}^{\prime}\right)\end{array}$ & $\begin{array}{l}\text { Reverse primers } \\
\left(\mathbf{5}^{\prime}-\mathbf{3}^{\prime}\right)\end{array}$ \\
\hline Human IFN- $\beta$ & AGGACAGGATGAACT & $\begin{array}{c}\text { TGATAGACATTAGCC } \\
\text { ATGACAG }\end{array}$ \\
Human GAPDH & GAGTCAACGGATTTG & $\begin{array}{c}\text { TTGATTTTGGAGGGA } \\
\text { TCTCG }\end{array}$ \\
Human RINCK & AGGAGGAGGAGG & CTGGACCTGCTCATG \\
& ACGGAG & CCACTG \\
Human Rsad2 & TTGGACATTCTCGCT & AGTGCTTTGATCTGT \\
& ATCTCCT & TCCGTC \\
HSV-1 RNA & TGGGACACATGCCTT & ACCCTTAGTCAGACT \\
& CTTGG & CTGTTACTTACCC \\
\hline
\end{tabular}




\section{Immunoprecipitation and immunoblotting}

Cells were lysed with lysis buffer $(20 \mathrm{mM}$ Tris-HCl, pH 7.5; 0.5\% Nonidet P-40; $250 \mathrm{mM} \mathrm{NaCl;} 3 \mathrm{mM}$ EDTA and $3 \mathrm{mM}$ EGTA) containing $20 \mathrm{mM} \mathrm{N}$-Ethylmaleimide and complete protease inhibitor cocktail (Roche, 04693132001), followed by centrifugation at $20,000 \times g$ for $20 \mathrm{~min}$ at $4{ }^{\circ} \mathrm{C}$. The supernatants were immunoprecipitated with anti-Flag M2 affinity beads. Cell lysates or immunoprecipitates were separated by SDS-PAGE and analyzed with immunoblotting. For the monoubiquitination detection, Cells were lysed with lysis buffer (20 mM Tris- $\mathrm{HCl}, \mathrm{pH}$ 7.5; 0.5\% Nonidet P-40; $250 \mathrm{mM}$ $\mathrm{NaCl} ; 3 \mathrm{mM}$ EDTA and $3 \mathrm{mM}$ EGTA) containing $20 \mathrm{mM}$ $N$-Ethylmaleimide and complete protease inhibitor cocktail (Roche, 04693132001), followed by sonicating for $1 \mathrm{~min}$ and centrifugation at $20,000 \times g$ for $20 \mathrm{~min}$ at $4{ }^{\circ} \mathrm{C}$. The supernatants were immunoprecipitated with antiHA antibody and analyzed with immunoblotting.

\section{Elisa}

PMA-differentiated U937 cells were seeded into 12-well plate at a density of $5 \times 10^{5}$ cells/well and treated as indicated. The secreted interferon in cell culture medium was analyzed with ELISA kits (41410, PBL).

\section{cGAMP quantitative analysis}

Cells were performed cGAMP extraction with extraction solvent [40:40:20 (v:v:v) methanol-acetonitrile-water] as described [43]. The quantification of cGAMP was performed on a triple-quadrupole mass spectrometer (Xevo TQ-S, Waters Corp. USA) equipped with an electrospray ionization source. The nebulizer gas was $99.95 \%$ nitrogen, and the collision gas was $99.99 \%$ argon with a pressure of $3 \times 10 \mathrm{E}-3 \mathrm{mbar}$ in the T-Wave cell. The gas flows of the cone and desolvation were set as 150 and $800 \mathrm{l} / \mathrm{h}$, respectively. The target compound measurements were performed in the positive mode with a $3.5 \mathrm{kV}$ capillary voltage, $120{ }^{\circ} \mathrm{C}$ source temperature, and $450{ }^{\circ} \mathrm{C}$ desolvation temperature. The optimized ion transitions were: cGAMP m/z $675 \rightarrow 524 ; \mathrm{m} / \mathrm{z} 675 \rightarrow 136$.

\section{Statistical analysis}

No statistical methods were used to estimate sample size. A standard two-tailed unpaired Student's $t$ test was used for statistical analysis of two groups. Statistical analyzed data are expressed as mean $\pm S D$. $P$ value $<0.05$ is considered as statistically significant. We performed the statistical analysis using GraphPad Prism.

\section{Abbreviations}

CGAMP: cyclic GMP-AMP; cGAS: cyclic GMP-AMP synthase; RINCK: RING finger protein that interacts with $C$ kinase; TRIM: tripartite motif protein; CRISPR/Cas9: clustered regularly interspaced short palindromic repeats and the endonuclease Cas9; HSV-1: herpes simplex virus 1; TBK1: TANK-binding kinase 1; IRF3: interferon regulatory factor 3 .

\section{Authors' contributions}

TL supervised the project; TL, ZL and XZ designed the experiments; ZL, ZZ, HC and $\mathrm{MZ}$ performed experiments; JD and JM performed mass spectrometry analysis; ZL, HC and TX analyzed the data; TL and ZL wrote the manuscript. All authors read and approved the final manuscript.

\section{Author details \\ ${ }^{1}$ State Key Laboratory of Proteomics, Institute of Basic Medical Sciences, National Center of Biomedical Analysis, 27 Tai-Ping Rd., Beijing 100850, China. \\ ${ }^{2}$ State Key Laboratory of Toxicology and Medical Countermeasures, Beijing Institute of Pharmacology and Toxicology, National Center of Biomedical Analysis, 27 Tai-Ping Road, Beijing 100850, China.}

\section{Acknowledgements}

We thank Jae U. Jung (University of Southern California) for providing the cGAS plasmid, Alexandra C. Newton (University of California at San Diego) for providing the RINCK plasmid, Jiahuai Han (Xiamen U, China) and Chunfu Zheng (Fujian Medical U, China) for providing HSV-1 virus.

\section{Competing interests}

The authors declare that they have no competing interests.

Availability of data and materials

All data generated or analyzed during this study are included in this article.

\section{Consent for publication}

Not applicable.

Ethics approval and consent to participate

Not applicable.

\section{Funding}

This work was supported by grants from China National Natural Science Foundation (Nos. 81771708, 81521064) and The National Key Research and Development Program of China (2017YFC1601100, 2015BAK45B01).

\section{Publisher's Note}

Springer Nature remains neutral with regard to jurisdictional claims in published maps and institutional affiliations.

Received: 25 March 2018 Accepted: 4 May 2018

Published online: 09 May 2018

\section{References}

1. Medzhitov R. Recognition of microorganisms and activation of the immune response. Nature. 2007;449(7164):819-26.

2. Gurtler C, Bowie AG. Innate immune detection of microbial nucleic acids. Trends Microbiol. 2013;21(8):413-20.

3. Wang XW, Wang JX. Pattern recognition receptors acting in innate immune system of shrimp against pathogen infections. Fish Shellfish Immunol. 2013;34(4):981-9.

4. Wu J, Chen ZJ. Innate immune sensing and signaling of cytosolic nucleic acids. Annu Rev Immunol. 2014;32:461-88.

5. Sun L, Wu J, Du F, Chen X, Chen ZJ. Cyclic GMP-AMP synthase is a cytosolic DNA sensor that activates the type I interferon pathway. Science. 2013;339(6121):786-91.

6. Li X, Shu C, Yi G, Chaton CT, Shelton CL, Diao J, Zuo X, Kao CC, Herr AB, Li P. Cyclic GMP-AMP synthase is activated by double-stranded DNAinduced oligomerization. Immunity. 2013;39(6):1019-31.

7. Wu J, Sun L, Chen X, Du F, Shi H, Chen C, Chen ZJ. Cyclic GMP-AMP is an endogenous second messenger in innate immune signaling by cytosolic DNA. Science. 2013;339(6121):826-30. 
8. Zhang X, Shi H, Wu J, Sun L, Chen C, Chen ZJ. Cyclic GMP-AMP containing mixed phosphodiester linkages is an endogenous high-affinity ligand for STING. Mol Cell. 2013;51(2):226-35.

9. Gao P, Ascano M, Zillinger T, Wang W, Dai P, Serganov AA, Gaffney BL, Shuman $S$, Jones RA, Deng $L$, et al. Structure-function analysis of STING activation by $\mathrm{c}\left[\mathrm{G}\left(2^{\prime}, 5^{\prime}\right) \mathrm{pA}\left(3^{\prime}, 5^{\prime}\right) \mathrm{p}\right]$ and targeting by antiviral DMXAA. Cell. 2013;154(4):748-62.

10. Xiao TS, Fitzgerald KA. The cGAS-STING pathway for DNA sensing. Mol Cell. 2013:51(2):135-9.

11. Crowl JT, Gray EE, Pestal K, Volkman HE, Stetson DB. Intracellular nucleic acid detection in autoimmunity. Annu Rev Immunol. 2017:35:313-36.

12. Ahn J, Barber GN. Self-DNA, STING-dependent signaling and the origins of autoinflammatory disease. Curr Opin Immunol. 2014;31:121-6.

13. Yang YG, Lindahl T, Barnes DE. Trex1 exonuclease degrades ssDNA to prevent chronic checkpoint activation and autoimmune disease. Cell. 2007;131(5):873-86.

14. Crow YJ, Hayward BE, Parmar R, Robins P, Leitch A, Ali M, Black DN, van Bokhoven $\mathrm{H}$, Brunner HG, Hamel BC, et al. Mutations in the gene encoding the 3'-5' DNA exonuclease TREX1 cause Aicardi-Goutieres syndrome at the AGS1 locus. Nat Genet. 2006:38(8):917-20.

15. Crow YJ, Manel N. Aicardi-Goutieres syndrome and the type I interferonopathies. Nat Rev Immunol. 2015;15(7):429-40,

16. Gao D, Li T, Li XD, Chen X, Li QZ, Wight-Carter M, Chen ZJ. Activation of cyclic GMP-AMP synthase by self-DNA causes autoimmune diseases. Proc Natl Acad Sci USA. 2015;112(42):E5699-705.

17. Gluck S, Guey B, Gulen MF, Wolter K, Kang TW, Schmacke NA, Bridgeman A, Rehwinkel J, Zender L, Ablasser A. Innate immune sensing of cytosolic chromatin fragments through cGAS promotes senescence. Nat Cell Biol. 2017;19(9):1061-70

18. Yang H, Wang H, Ren J, Chen Q, Chen ZJ. cGAS is essential for cellular senescence. Proc Natl Acad Sci USA. 2017:114(23):E4612-20.

19. Liang Q, Seo GJ, Choi YJ, Kwak MJ, Ge J, Rodgers MA, Shi M, Leslie BJ, Hopfner KP, Ha T, et al. Crosstalk between the cGAS DNA sensor and Beclin-1 autophagy protein shapes innate antimicrobial immune responses. Cell Host Microbe. 2014;15(2):228-38.

20. Seo GJ, Yang A, Tan B, Kim S, Liang Q, Choi Y, Yuan W, Feng P, Park HS, Jung JU. Akt kinase-mediated checkpoint of cGAS DNA sensing pathway. Cell Rep. 2015:13(2):440-9.

21. Xia P, Ye B, Wang S, Zhu X, Du Y, Xiong Z, Tian Y, Fan Z. Glutamylation of the DNA sensor CGAS regulates its binding and synthase activity in antiviral immunity. Nat Immunol. 2016;17(4):369-78.

22. Davis ME, Gack MU. Ubiquitination in the antiviral immune response. Virology. 2015;479-480:52-65.

23. Malynn BA, Ma A. Ubiquitin makes its mark on immune regulation. Immunity. 2010;33(6):843-52.

24. Chen M, Meng Q, Qin Y, Liang P, Tan P, He L, Zhou Y, Chen Y, Huang J, Wang RF, et al. TRIM14 inhibits cGAS degradation mediated by selective autophagy receptor p62 to promote innate immune responses. Mol Cell. 2016;64(1):105-19.

25. Wang Q, Huang L, Hong Z, Lv Z, Mao Z, Tang Y, Kong X, Li S, Cui Y, Liu H, et al. The E3 ubiquitin ligase RNF185 facilitates the CGAS-mediated innate immune response. PLoS Pathog. 2017;13(3):e1006264.

26. Chen D, Gould C, Garza R, Gao T, Hampton RY, Newton AC. Amplitude control of protein kinase $\mathrm{C}$ by RINCK, a novel E3 ubiquitin ligase. J Biol Chem. 2007:282(46):33776-87.
27. Yang W, Xia Y, Cao Y, Zheng Y, Bu W, Zhang L, You MJ, Koh MY, Cote G, Aldape K, et al. EGFR-induced and PKCepsilon monoubiquitylationdependent NF-kappaB activation upregulates PKM2 expression and promotes tumorigenesis. Mol Cell. 2012;48(5):771-84.

28. Li XD, Wu J, Gao D, Wang H, Sun L, Chen ZJ. Pivotal roles of CGAS-cGAMP signaling in antiviral defense and immune adjuvant effects. Science. 2013;341(6152):1390-4.

29. Su C, Zheng C. Herpes simplex virus 1 abrogates the cGAS/STING-mediated cytosolic DNA-sensing pathway via its virion host shutoff protein, UL41. J Virol. 2017;91 (6):e02414-16.

30. Chan YK, Gack MU. Viral evasion of intracellular DNA and RNA sensing. Nat Rev Microbiol. 2016;14(6):360-73.

31. Yoh SM, Schneider M, Seifried J, Soonthornvacharin S, Akleh RE, Olivieri KC, De Jesus PD, Ruan C, de Castro E, Ruiz PA, et al. PQBP1 is a proximal sensor of the CGAS-dependent innate response to HIV-1. Cell. 2015;161(6):1293-305.

32. Bhoj VG, Chen ZJ. Ubiquitylation in innate and adaptive immunity. Nature. 2009:458(7237):430-7.

33. Fuchs SY. Ubiquitination-mediated regulation of interferon responses. Growth Factors. 2012:30(3):141-8.

34. McNab FW, Rajsbaum R, Stoye JP, O'Garra A. Tripartite-motif proteins and innate immune regulation. Curr Opin Immunol. 2011;23(1):46-56.

35. Kawai T, Akira S. Regulation of innate immune signalling pathways by the tripartite motif (TRIM) family proteins. EMBO Mol Med. 2011;3(9):513-27.

36. Seo GJ, Kim C, Shin WJ, Sklan EH, Eoh H, Jung JU. TRIM56-mediated monoubiquitination of CGAS for cytosolic DNA sensing. Nat Commun. 2018;9(1):613.

37. Hu MM, Yang Q, Xie XQ, Liao CY, Lin H, Liu TT, Yin L, Shu HB. Sumoylation promotes the stability of the DNA sensor CGAS and the adaptor STING to regulate the kinetics of response to DNA virus. Immunity. 2016:45(3):555-69.

38. Cui Y, Yu H, Zheng X, Peng R, Wang Q, Zhou Y, Wang R, Wang J, Qu B, Shen $\mathrm{N}$, et al. SENP7 potentiates CGAS activation by relieving SUMO-mediated inhibition of cytosolic DNA sensing. PLoS Pathog. 2017;13(1):e1006156.

39. Barber GN. STING: infection, inflammation and cancer. Nat Rev Immunol. 2015:15(12):760-70.

40. Girardin SE, Boneca IG, Carneiro LA, Antignac A, Jehanno M, Viala J, Tedin K, Taha MK, Labigne A, Zahringer U, et al. Nod1 detects a unique muropeptide from gram-negative bacterial peptidoglycan. Science. 2003;300(5625):1584-7.

41. Woodward JJ, lavarone AT, Portnoy DA. c-di-AMP secreted by intracellular Listeria monocytogenes activates a host type I interferon response. Science. 2010;328(5986):1703-5.

42. Shi J, Zhao Y, Wang K, Shi X, Wang Y, Huang H, Zhuang Y, Cai T, Wang F, Shao F. Cleavage of GSDMD by inflammatory caspases determines pyroptotic cell death. Nature. 2015;526(7575):660-5.

43. Wu C, Cheng YY, Yin H, Song XN, Li WW, Zhou XX, Zhao LP, Tian L, Han JC, Yu HQ. Oxygen promotes biofilm formation of Shewanella putrefaciens CN32 through a diguanylate cyclase and an adhesin. Scientific reports. 1945;2013:3.

Ready to submit your research? Choose BMC and benefit from

- fast, convenient online submission

- thorough peer review by experienced researchers in your field

- rapid publication on acceptance

- support for research data, including large and complex data types

- gold Open Access which fosters wider collaboration and increased citations

- maximum visibility for your research: over 100M website views per year

At BMC, research is always in progress.

Learn more biomedcentral.com/submissions 